\title{
SCHOLASTIC AND INTELLIGENCE TESTS.
}

BY

\author{
A. DINGWALL FORDYCE, M.D., F.R.C.P.Ed., \\ Physician, Royal Liverpool Children's Hospital.
}

Tests of scholastic ability and of general intelligence have been in use for several years, mainly in connection with the certification of mental defect in the legal sense.

Mental defect in this sense is, owing to the terms of definition in the Mental Deficiency Act, 1913, much more common among the child population than the adult, and it is stated (Cyril Burt, " Mental and Scholastic Tests," L.C.C., p. 173) that roughly one-third of the children certified as mentally defective and educated in a Special Day School will on leaving school at the age of 16 have sufficient intelligence to manage their practical affairs and consequently will no longer be certifiable as mentally defective.

This position arises because of the definition of the term feeble-minded persons, which is " persons in whose case there exists from birth or frorn an early age mental defectiveness not amounting to imbecility yet so pronounced that they require care, supervision and control for their own protection or for the protection of others, or, in the case of children, that they by reason of such defectiveness appear to be permanently incapable of receiving proper benefit from the instruction in ordinary schools."

It is those children who are certified mentally defective in this sense by the certifying medical officers of the Education Authorities who are suitable for instruction in a Special School for mentally defective children.

The category certainly includes many children who would not be designated mentally defective by pure medical clinicians, as a result of ordinary clinical examination, and in the light of conventional medical training and standard (hospital, institution, general practice). Undoubtedly these borderline children benefit scholastically by special educational facilities, but, as the term mental defect carries with it commonly a stigma, it would appear that advantage might be derived from restriction of the term to a more purely medical basis, with some other term applicable to the cases more purely scholastic or educational.

When dealing with possible mental defect in the legal sense, the certifying officer, apart from personal examination, has two main sources of aid in forming an opin:on-the school reports and the intelligence quotient.

Of the cases of suspected mental defect which have come before me in such a capacity during the past 15 months, I find that 1,000 have been tested by Prof. Burt's revision of the Binet-Simon tests. I endeavoured in every case to form my own opinion in the light of the legal instructions, and so far as possible to be not unduly swayed either by anomalies in the home or school. or by other opinions or tests. The tests were in all cases 
carried out under the immediate direction of the Lady Superintendent of the Special Schools. I do not think any clinician of experience is naturally swayed by cut-and-dry tests for general application, and I cannot feel that $I$ in any way exalted the importance of the Binet-Simon results in forming my individual opinion.

Of the 1,000 children, 293 were diagnosed as dull and backward, or dull or backward; 44 were certified physically defective; 143 were certifiel imbecile or idiot; and 520 were certified feeble-minded, and therefore suitable for education in a Special Day School for mentally defective children.

The relative proportion of the figures in the different categories is here of no significance. Special circumstances were attached to some of the examinations, and from 200 to $3 \mathrm{CO}$ other children were in addition certified in one or other of the four categories without Binet-Simon tests being made.

As these children were all referred to me as cases of suspected mental defect, I have bracketed the figures for the physical defectives with those for the dull and backward in order to obtain a clear-cut comparison between this combined dull and backward group and the feeble-minded.

The tabulated results of the tests show the following figures:-

\begin{tabular}{|c|c|c|c|c|c|c|c|c|c|c|c|c|}
\hline \multicolumn{3}{|l|}{ I.Q. } & $\begin{array}{l}95 \text { or } \\
\text { under. }\end{array}$ & $\begin{array}{c}25 \text { to } \\
50\end{array}$ & $50 \div$ & $60+$ & $70+$ & $80+$ & $90+$ & $100+$ & \multicolumn{2}{|c|}{ Total Cases. } \\
\hline \multicolumn{3}{|c|}{ Dull or backward or both... } & - & - & 10 & 52 & 112 & 76 & 25 & 18 & $293)$ & \\
\hline \multirow{2}{*}{\multicolumn{2}{|c|}{ Physically defoctive }} & \multirow[t]{2}{*}{$\cdots$} & 一 & 一 & 3 & 12 & 17 & 7 & 3 & 2 & .44 & \\
\hline & & & - & - & 13 & 64 & 129 & 83 & 28 & 20 & - & 337 \\
\hline Feeble-minded & & $\ldots$ & - & 48 & 140 & 208 & 117 & 7 & - & - & - & 520 \\
\hline \multirow[t]{2}{*}{ Imbecile or idiot } & \multirow{2}{*}{\multicolumn{2}{|c|}{$\cdots$}} & 10 & 37 & 36 & 6 & 4 & - & 一 & 一 & - & 140 \\
\hline & & & - & - & - & - & $1-$ & - & - & - & - & 1,000 \\
\hline
\end{tabular}

I find from the figures in this particular series that for dull and backward children the common quotient is in the late seventies, while for educable mental defectives it is in the early sixties. The quotient is, at best, one aid to a decision regarding the individual, but it is an important one. The decision is influenced by various circumstances apart from it, e.g., character cases, etc., and the quotient itself varies in significance according to age, whether scholastic or intelligence failure, etc., and to some such conditions the unusually higher quotients among those here noted are due.

Intelligence tests are in many instances valuable for the practitioner. This is particularly the case for patients with physical defects who suffer from long-continued or recurrent ailments, and on the mental side for cases of scholastic retardation or character anomalies. Chorea, neuropathies generally. and paralytic cases are frequently examples of a combined physical and mental defect, and here scholastic combined with intelligence tests often give most valuable information as to ætiology, prognosis and desirable procedure. 